\title{
Stakeholders Selection for Interorganizational Systems: A Systematic Approach
}

\author{
Luciana C. Ballejos ${ }^{1}$ and Jorge M. Montagna ${ }^{1,2}$ \\ 1 CIDISI - FRSF Universidad Tecnológica Nacional \\ Lavaise 610 - (3000) Santa Fe - Argentina \\ lballejo@frsf.utn.edu.ar \\ 2 INGAR - Instituto de Desarrollo y Diseño \\ Avellaneda 3657 - (3000) Santa Fe - Argentina \\ mmontagna@ceride.gov.ar
}

\begin{abstract}
Stakeholders identification is a critical task for successful software projects. In general, there are no methodologies that allow performing it in a systematic way. Besides, several facts must be analyzed when the project is carried out in a context formed by multiple organizations. The complexity of these environments makes the task extremely hard. To face these difficulties, stakeholders are defined and analyzed taking into account the characteristics of the interorganizational dimension. Also a methodology is proposed for carrying out their identification that allows systematically specifying all people, groups and organizations whose interests and needs are affected by the information system in all the involved dimensions.
\end{abstract}

\section{Introduction}

Stakeholders are the primary source of requirements for any software project [1]. They are defined as any group or individual that can affect or be affected by the achievement of an organization's objectives or that must be involved in a project because they are affected by its activities or results [2].

Big software projects involve a great number of stakeholders with different expectations that can be controversial [3, 4]. They can also be geographically dispersed. Thus, the action of appropriately involving the relevant ones is highly important for success $[5,6]$. However, there are few authors that have studied the stakeholder concept applied to contexts formed by multiple organizations, generally called Interorganizational Networks (IONs), where usually opposed and competitive interests and cultures coexist. Some of the authors working in this area are Pouloudi [7], Sharp et al. [8] and Kotonya and Sommerville [9], who suggest integral definitions of the term. A holistic concept of all the others can be provided, which states that a stakeholder of an interorganizational information system (IOS) is any 
individual, group, organization or institution that can affect or be affected (in a positive or negative way) by the system under study and that has direct or indirect influence on the requirements. This definition is similar to the traditional one, but extended to include also firms that interact in interorganizational (IO) contexts.

Even though there is a concept of stakeholder that may be applied to these environments, there are no practical models for their identification when the interorganizational dimension must be incorporated [10]. Pouloudi and Whitley [11], for example, present principles, without posing clear tasks to obtain concrete results with an adequate degree of consistency and reliability. To counteract this, a systematic approach for selecting stakeholders for these environments is presented.

\section{Stakeholder Types}

Different types of stakeholders exist in each project. In general, there is a lack of understanding regarding types and ideal candidates. This has incidence on the nonexistence of systematic approaches for efficiently identifying them [12]. Bittner and Spence [1] propose to start involving stakeholders by first identifying different types. We define stakeholder type as the classification of sets of stakeholders sharing the same characteristics in relation to the context under analysis.

Traditional identification of types of stakeholders is focused on those inside the organization under study. This constitutes an inappropriate reference framework, since valuable information for a correct interpretation of the problem is missed [2, 13]. For IOSs there exists the need of incorporating the interorganizational dimension. It is also necessary to avoid focusing only on those stakeholders directly related to the development and use of systems, such as users and developers $[5,12$, 14]. A more reality-adjusted one is necessary [11]. The traditionally used term "internal" must be extended. There are not only stakeholders inside the firm, but also stakeholders inside the ION, who will take care of the common objectives at network level. Stakeholders inside each firm represent some particular firm. Those inside the ION pursue interorganizational objectives, representing the network interests, which many times do not coincide with those of individual firms.

Another distinction can be made between internal and external stakeholders, depending on whether they are previously involved in organizations (manager, employee, etc.) or they are included because of having a necessary vision for this particular project (customers, suppliers, auditors, regulators, experts, etc.) [5, 13].

\section{Stakeholder Roles}

Besides the attributes held by stakeholders regarding the context in which they are included, it is necessary to take into account the roles they play during the project. A stakeholder role may be defined as a collection of defined attributes that characterize a stakeholder population, its relationship with the system and its impact or influence on the project. 
Even though several authors focus role analysis on users and developers (or technicians) of an information system, there are others that should be studied as well $[3,12,14,15]$. The most used in the literature are described in Table $1[15,16,17$, $18,19]$. They might be represented in any project.

Table 1. Stakeholder Roles.

\begin{tabular}{|c|}
\hline $\begin{array}{l}\text { Beneficiary: Those that benefit from the system implementation. } \\
\text { - Functional: Those that benefit directly from the functions performed by the system and its products or results. Other } \\
\text { information systems that interact with the new one can be included in this role. } \\
\text { - Financial: Those that benefit indirectly from the system, obtaining financial rewards. } \\
\text { - Political: They benefit indirectly from the system, obtaining political gains in terms of power, influence and/or prestige. } \\
\text { - Sponsor: Those in charge of the project. They start the system development, collect funds and protect it against political } \\
\text { pressures and budget reductions, etc. They are in charge of providing authority and guidance, and respecting priorities. }\end{array}$ \\
\hline $\begin{array}{l}\text { Negative: Those that undergo some kind of damage as a consequence of the system implementation or are adversely } \\
\text { impacted by its development (for example, losing their jobs or power for decision making, physical or financial damage, etc.). }\end{array}$ \\
\hline $\begin{array}{l}\text { Responsible: They are in charge of the system development in all phases. This type includes people working with budgets } \\
\text { and agreed times (e.g.: project manager, developers, responsible for selecting suppliers, etc.). }\end{array}$ \\
\hline $\begin{array}{l}\text { Decision-Maker: Those that control the process and make decisions to reach agreements. They define the way in which } \\
\text { consensus is attained throughout the project. }\end{array}$ \\
\hline $\begin{array}{l}\text { Regulator: Also called "legislator" [8]. They are generally appointed by government or industry to act as regulators of } \\
\text { quality, security, costs or other aspects of the system. They generate guidelines that will affect the system development } \\
\text { and/or operation. For instance, health organisms that control standards, non-governmental organisms, organisms that } \\
\text { defend rights, organisms related to legal, tax controls, etc. }\end{array}$ \\
\hline $\begin{array}{l}\text { Operator: They are also called "users" by many authors }[14,15] \text {. They operate the system to be developed. They interact } \\
\text { with the system and use its results (information, products, etc.). They are different from functional beneficiaries, even though } \\
\text { their roles may overlap. An operator can benefit form the system or not. }\end{array}$ \\
\hline $\begin{array}{l}\text { Expert: They are familiar with functionalities and consequences of the system implementation. They widely know the } \\
\text { implementation domain and can collaborate in the requirements elicitation to a great extent. }\end{array}$ \\
\hline $\begin{array}{l}\text { Consultant: Include any role dealing with providing support for any aspect of the system development. They are generally } \\
\text { external to the organization and have specific knowledge on a particular area. }\end{array}$ \\
\hline
\end{tabular}

\section{Methodology for Stakeholders Identification in IO Environments}

Existing approaches for identifying stakeholders do not provide enough tools or concrete techniques, even in organizational environments [8]. Many consider stakeholders as a default product of a non-explained identification process [11]. But their selection is a key task, since all important decisions during the project are made by them. Thus, a methodology for guiding their identification in IO environments is proposed. It is composed by steps which are described in the following subsections.

\subsection{Specify the Types of Stakeholders to be Involved in the Project}

This step specifies the types of stakeholders the project will count on, analyzing the various existing contexts. Using the previously presented stakeholder type concept, a framework is introduced in Table 2. It allows performing an analysis by starting from different criteria applied to different dimensions, thus a profile characterization of the stakeholders to be involved is obtained.

After analyzing the specific needs in an IO context from different examples, a basic set of criteria was defined. It provides elements to characterize the stakeholders involved. Nevertheless, this set may be extended according to the specific needs of certain environments and IOSs. Each criterion identifies different points of view, needs or influences on the IOS development. They must be applied to each dimension in the work space (organizational, interorganizational and external). 
Table 2. Multidimensional framework for stakeholders identification.

\begin{tabular}{|c|c|c|c|c|}
\hline & & \multicolumn{3}{|c|}{ \$ELECTION DIMENSION } \\
\hline & & \multicolumn{2}{|c|}{ TITERUAL } & \multirow{2}{*}{ EXIERWAL } \\
\hline & & ORG & ION & \\
\hline \multirow{4}{*}{ 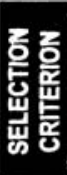 } & FUNCTION (functions or processes affected by the IOS) & & & \\
\hline & GEOGRAPHICAL (geographical regions affected by the project) & & & \\
\hline & $\begin{array}{l}\text { KNOWLEDGE/ ABILITIES (abilities and knowledge about the IOS } \\
\text { application domain) }\end{array}$ & & & \\
\hline & HIERARCHICAL LEVEL (involved structural levels) & & & \\
\hline
\end{tabular}

\subsubsection{Function Criterion}

Implies the analysis of functions or tasks that will be affected by the IOS, either directly (because the system will support them) or indirectly (because IOS outputs and results will be used by them). Its application to the organizational dimension is intended to select stakeholders of each function affected by the IOS in each firm.

This criterion applied to the ION dimension identifies the main activities that take place in the network, basis for collaboration among organizations. Representatives of the integrated process must be involved, who will defend interorganizational interests, rather than individual or organizational ones. At external level, attention is focused on organizations that are external to the ION when the IOS somehow modifies their interaction with the network.

\subsubsection{Geographical Criterion}

This criterion identifies stakeholders located in different geographical places, with cultural and idiomatic differences, etc., since the organizations may be geographically dispersed. Organizational dimension considers geographical dispersion at firm level. It specifies the inclusion of stakeholders belonging to each branch or enclave of each firm. On the other hand, the network can have dispersed units, from which stakeholders must be selected. It will also be necessary to count on stakeholders that represent the geographical dispersion of external organizations whose relations with ION members will be modified by the IOS.

\subsubsection{Knowledge / Abilities Criterion}

This criterion is important to involve stakeholders having specific knowledge or abilities about the information universe underlying the IOS implementation domain. At organizational level, specific abilities for internal tasks in each organization must be analyzed. Attention must be placed on stakeholders having technical knowledge on modules or applications that will interact with the IOS. In the ION dimension, aspects to be taken into account are: interorganizational processes, supporting technologies, characteristics of interactions, etc. There may be also entities external to the ION with experience in the IOS implementation area or in the processes it will support, such as consultants or experts in technologies. 


\subsubsection{Hierarchical Level Criterion}

The analysis is intended to involve stakeholders from every level affected by the IOS. Structures and decision flows must be studied. In the organizational dimension, stakeholders must be selected from every hierarchical level of each organization. At ION level, there is also a structure that can allow for different formalization degrees, according to each particular case. Each decision level must be involved. Also structures from external organizations must be included for the external dimension.

\subsection{Specify the Roles to be Included in the Project}

This step specifies the roles that will be included in the project. It is generic, since it has similar results in any example it is applied to. It can be performed simultaneously to the Step 1. Its results make the project manager become aware of the scope and time of participation of each particular role during the project.

The greatest possible quantity of the roles described in Table 1 will be represented. Charts like the presented in Table 3 must be generated. There Bittner and Spence [1] describe each role and present details of the associated responsibilities and participation frequency. "Participation" attribute significantly varies from one project to another, since it depends on the objectives of the project that is being executed and on personal estimations of the project manager.

Table 3. Information to be specified of each stakeholder role [1].

- Name: Stakeholder Role Name.

- Brief Description: Briefly describing the role and what it represents for the project. The stakeholder represents a group of stakeholders, some aspect of the participating organizations, or some other affected business area.

- Responsibilities: Summarizing key responsibilities in relation to the project and to the system to be developed. Specifying the value the role will provide to the project team. For example, some responsibilities may be monitoring the project progress, specifying expenditure levels and approving funds spending, etc.

- Participation: Briefly describe how they will be involved in the project and in which stages they will have influence.

\subsection{Select Stakeholders}

This task is based on Table 2 developed in Step 1. It has the objective of guiding the selection of entities having the characteristics identified previously. By analyzing the different criteria in the various dimensions, the project manager must identify concrete stakeholders that match that profile. The various profiles may be represented by individuals, groups, organizations, or a combination of them.

Characteristics of the selected stakeholders must be documented (Table 4). Rows show the different identified entities, through an ID and a name for each stakeholder, a brief description, the criteria used and the corresponding dimension. The last columns are completed in the following steps. 
Table 4. Information to be gathered from each selected stakeholder.

\begin{tabular}{|c|c|c|c|c|c|c|c|}
\hline \multirow{2}{*}{ (i) } & \multirow{2}{*}{ STAKEHOLDER } & \multirow{2}{*}{ Description } & \multicolumn{2}{|c|}{ TYPE } & \multirow{2}{*}{ ROLE } & \multirow{2}{*}{$\begin{array}{l}\text { TWERESTI } \\
\text { MPORIANCE }\end{array}$} & \multirow{2}{*}{ INFUUENCE } \\
\hline & & & Critaion & Diminsion & & & \\
\hline S1 & & & & & & & \\
\hline S2 & & & & & & & \\
\hline Sn & & & $\ldots$ & $\ldots$ & & & \\
\hline
\end{tabular}

\subsection{Associate Stakeholders with Roles}

The roles of the stakeholders selected in Step 3 are specified, using the charts created in Step 2 (Table 3). The first subtask is to restrict the set of roles each stakeholder can represent. Table 5 must be filled to associate the different options resulting from the analysis of the various criteria in all dimensions (rows) to the diverse roles a stakeholder with those attributes might play (columns).

The project manager must estimate the roles that can be played by certain criterion option and mark the corresponding intersection. Marked cells will represent the existence of a generic relationship between a particular stakeholder type and the roles it might be associated with, according to the attributes that define the type.

Table 5. Stakeholders Type-Roles Relationship.

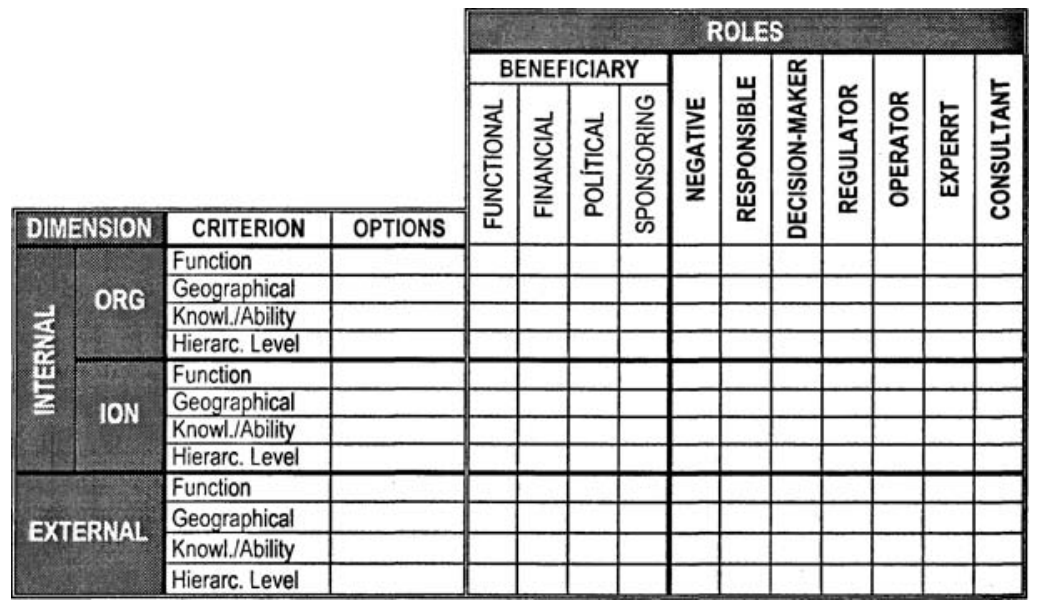

The second subtask is more concrete. During it, the manager must decide the role/s each stakeholder identified in Table 4 will play and record this in the "Stakeholder Role" column. To facilitate the analysis, Table 5 must be used. Paying attention to the different options of criteria and dimensions that gave rise to the selection of a particular stakeholder, the manager must decide which of the marked roles will be definitely represented by that entity.

Sometimes, the roles associated to a particular type of stakeholder may be contradictory. As a consequence, the manager will have to decide (possibly together with the stakeholders) on the role they will be definitely assigned. 


\subsection{Analyze the Importance and Influence of Stakeholders}

Several authors propose the analysis of the importance (or interest) and the influence stakeholders have in a project before being included $[20,21,22,23]$. The importance indicates the extent to which the project cannot be considered successful if his needs and expectations are not managed. The project success is important for some stakeholders (e.g. beneficiaries). Others have a relatively low importance. In the same way, some stakeholders have greater power and influence on the project decisions, which influences the project design, implementation and results. Anyway, it is important to have exact understanding of stakeholders' importance to determine interests' priorities at future stages of the project. The criteria and the distinction between roles associated to the stakeholders (Step 4) greatly facilitate this task.

With the aim of having a general view of the different degrees of importance and influence of all stakeholders, they are placed on the matrix shown in Table 6, where each stakeholder is located in some of the presented quadrants. Also, with this information, Interest/Importance and Influence columns of Table 4 must be filled.

Table 6. Stakeholders Matrix.

\begin{tabular}{|c|c|c|c|}
\hline & \multicolumn{2}{|c|}{ INFLUENCE } \\
\hline & & $\mathrm{HIGH}$ & LOW \\
\hline \multirow{2}{*}{ 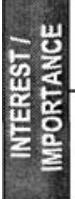 } & 폼 & Constitute the supporting base of the project. & $\frac{\text { B }}{\text { Need special initiatives. }}$ \\
\hline & 혹 & $\begin{array}{l}\text { Can influence results, but their priorities are not the } \\
\text { same as those of the project. This may constitute a } \\
\text { risk or an obstacle for the project. }\end{array}$ & Least important stakeholders for the project. \\
\hline
\end{tabular}

Quadrant A: Some stakeholders may have much influence and even be very interested in the project. It is vital to understand these stakeholders' viewpoints, especially their potential objections. Such is the case, for example, of those that are sure that their interests and needs will be satisfied with the system and that have power for decision-making and/or influence on financing sources for the project.

Quadrant B: They are highly interested in the project, but their influence may be small. If they are in favor of it, they are valuable sources of information: they can accede to relevant documents and help in identifying challenges.

Quadrant C: They will not pay attention to the project details, since they consider that it does not affect them. However, they have influence on the project success: for example, they can vote for the project approval.

Quadrant D: The least possible amount of time must be devoted to these stakeholders. They are not interested in the project and are not in such a position that can help the project manager to perform his job.

Once these tasks are finished, concrete stakeholders having a particular interest in the IOS development have been identified. Also the roles they can play during the initial stages of the project were associated to each one, basing the analysis on their profiles. There is also an initial idea of the importance and influence they can have on the project. After this identification activity, the requirements elicitation remains. 


\section{Example}

A project developed in the United Kingdom and encouraged by the National Health Service (NHS) has been selected to show the application of the presented methodology. It was previously used by other authors [2]. It has been enriched with information extracted from NHS webpage to have a more real vision of the problem [24]. It is a written case study where the proposed approach is applied in retrospect.

Authorities and Trusts are the different types of organizations that run the NHS at a local level. England is split into 28 Strategic Health Authorities (SHAs). They are responsible for managing local organizations on behalf of the English Department of Health. Within each SHA, the NHS is split into various types of Trusts that take responsibility for running different services in each local area. They group hospitals, organizations that work in health and social care, ambulance services, or first services (e.g.: doctors, dentists, pharmacists). All participating organizations will become part of a Trust and will be managed by an SHA. They are the main entities in the ION. Its external entities are patients, auditing committees, other government areas, medicines suppliers, educational institutions, etc.

The project is called Integrated Care Record Service (ICRS). It involves the design of an information system for managing a wide set of services that cover generation, movement and access to health files. It includes workflow capacities for managing and recording the movement of patients throughout all entities in the NHS. The main goal is the transformation of the current model of separated systems circumscribed to organizational structures into a globalizing model. ICRS will include e-prescribing, e-booking, delivering patient information such as test results and prescription information on-line and so on [25]. The previous utilization of information systems, applications and local data bases in member organizations should be taken into account. They must be integrated to the IOS.

The following lines present the results to be obtained if the methodology proposed is applied in this example. It does not constitute an exhaustive application. It is only intended to show its usefulness and some results that may be reached.

\subsection{Step 1. Specify the Types of Stakeholders to be Involved in the project}

Table 7 includes examples of the different criteria in the existing dimensions.

\subsection{Step 2. Specify the Roles to be Included in the Project}

A basic chart corresponding to the Operator role is shown as example (Table 8).

\subsection{Step 3. Select Stakeholders}

Various stakeholders can be identified with Table 7. Table 9 present some of them, with the information required for this step. It shows a unique occurrence of stakeholders with a certain profile. There may be cases in which different ones share the same profile but represent different organizations, regions, etc. Each of them will have a different input in the table. 
Table 7. Types of Stakeholders for ICRS System.

\begin{tabular}{|c|c|c|c|}
\hline & \multicolumn{3}{|c|}{ SELECTION DIMENSION } \\
\hline & \multicolumn{2}{|c|}{ INTERYAL } & \multirow{2}{*}{ EXTERNAL } \\
\hline & ORGANIZATION & ION & \\
\hline zo & $\begin{array}{l}\text { Administrative Processes: } \\
\text { Hospital Admission } \\
\text { Process; Bed and Waiting } \\
\text { list management; Master } \\
\text { Patient Index } \\
\text { maintenance; Booking. } \\
\text { Clinical Processes: } \\
\text { Special Services; } \\
\text { Biochemical Analyses; } \\
\text { Prescribing; Emergencies } \\
\text { Management; Care Plans } \\
\text { and Assessments. } \\
\end{array}$ & $\begin{array}{l}\text { - Planning Processes for stock } \\
\text { management and medicines } \\
\text { distribution. } \\
\text { - Material Supplying. } \\
\text { - Purchase of high complexity } \\
\text { equipment. } \\
\text { - National Integrated Process } \\
\text { of urgencies and patients } \\
\text { derivation. } \\
\text { - SHAs: relations and } \\
\text { partnerships with universities } \\
\text { and education institutions. }\end{array}$ & $\begin{array}{l}\text { - Patients. There exist diverse forums, } \\
\text { commissions and committees for patients from } \\
\text { which stakeholders can be selected: } \\
\text { - Public Advisory Board (PAB). } \\
\text { - Patients Forums. } \\
\text { - Auditor Committees: to evaluate IOS results. } \\
\text { - Government Areas that impose rules or } \\
\text { conditions to the IOS functions and to the } \\
\text { information that it will manage. } \\
\text { - Laboratories and suppliers. }\end{array}$ \\
\hline 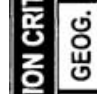 & $\begin{array}{l}\text { Branches, dependencies, } \\
\text { etc. of participating } \\
\text { organizations. }\end{array}$ & $\begin{array}{l}\text { - Medicines distribution centers. } \\
\text { - Regional Health Departments. } \\
\text { - Strategic Health Authorities. }\end{array}$ & $\begin{array}{l}\text { - Geographical locations of the patients. } \\
\text { - National branches of the laboratories that supply } \\
\text { drugs and medicines to the ION organizations. }\end{array}$ \\
\hline 总 & $\begin{array}{l}\text { - Operators of the } \\
\text { existing systems and } \\
\text { that should interact } \\
\text { with the ICRS. } \\
\text { - Those in charge of the } \\
\text { Informatics Area. } \\
\text { - Organization's own } \\
\text { standards. }\end{array}$ & $\begin{array}{l}\text { - Health Improvement and } \\
\text { Modernization Programmes. } \\
\text { - Specialists in Health matters } \\
\text { (e.g.: Quality Standards) } \\
\text { - Promoters for the integrity of } \\
\text { health information. } \\
\text { - National analytical services } \\
\text { (to provide expert intelligence } \\
\text { to add value, through analysis } \\
\text { and interpretation, and to } \\
\text { promote Information sharing). }\end{array}$ & $\begin{array}{l}\text { - Specialist in process redesign: to review issues } \\
\text { of current practices, best practices guidelines } \\
\text { and design new integrated processes. } \\
\text { - National Clinical Advisory Board (NCAB). It is a } \\
\text { committee to represent healthcare professionals } \\
\text { (consultants, nurses, dentists, and pharmacists). } \\
\text { - NHS Information Standards Board (ISB): to } \\
\text { determine information standards for the system. } \\
\text { - Universities and other education institutions. } \\
\text { - Specialists in technology to be employed for IOS } \\
\text { development. }\end{array}$ \\
\hline$\vec{x}$ & $\begin{array}{l}\text { Organizational authorities: } \\
\text { hierarchical levels of each } \\
\text { participating entity. }\end{array}$ & $\begin{array}{l}\text { - English Department of Health. } \\
\text { - Strategic Health Authorities. } \\
\text { - Trusts. }\end{array}$ & $\begin{array}{l}\text { - Hierarchical levels involved of the government } \\
\text { areas, laboratories, suppliers, educational } \\
\text { institutions. }\end{array}$ \\
\hline
\end{tabular}

Table 8. Example of Operator Role Description.

- Name: Operator.

- Brief Description: It represents people and groups that interact directly with the IOS.

- Responsibilities: It must express needs and requirements for the normal operation of the system to be developed. They must test proceedings adjustments and suggest modifications according to their experience. They must revise documentation of proceedings and functionalities.

- Participation: It will participate at different stages of the project:

- Stage of functional and non-functional requirements elicitation (e.g. design/approval of use cases).

- Stage of Proceedings Development after Design and Codification.

- Stage of Transition and test of the svstem to be imblemented.

\subsection{Step 4. Associate Stakeholders with Roles}

Table 10 associates possible roles to different criteria and dimensions previously specified. Then, the decided roles each stakeholder will play must be specified (Table 11). This must be included in the "Role" column of Table 9.

\subsection{Step 5. Analyze the Importance and Influence of Stakeholders}

Table 12 shows each stakeholder's interest and influence. This information must be reflected in the last two columns of Table 9 and is used to develop Table 13. 
Table 9. Stakeholders Chart for ICRS (last 3 columns of Table 4 are omitted).

\begin{tabular}{|c|c|c|c|c|}
\hline \multirow{2}{*}{ (D) } & \multirow{2}{*}{ STAKEHOLDER } & \multirow{2}{*}{ Description } & \multicolumn{2}{|c|}{ TYPE } \\
\hline & & & Criterion & Dimension \\
\hline S1 & $\begin{array}{l}\text { Biochemists Group } \\
\text { Organization } \mathbf{X}\end{array}$ & $\begin{array}{l}\text { They perform their activities in laboratories of Organization } \\
\text { X. Their tasks will be modified. }\end{array}$ & Function & $\begin{array}{l}\text { Organiz. } \\
\text { (Hospital X) }\end{array}$ \\
\hline \multirow{2}{*}{ S2 } & \multirow{2}{*}{ Patient A } & \multirow{2}{*}{$\begin{array}{l}\text { Persons who will use health public services, whose } \\
\text { information will be managed by the IOS. It will be } \\
\text { associated to a particular region (Region A). }\end{array}$} & Function & \multirow{2}{*}{ External } \\
\hline & & & Geograph. & \\
\hline S3 & $\begin{array}{l}\text { Director of the English } \\
\text { Department of Health }\end{array}$ & $\begin{array}{l}\text { Pursues political goals and interests of the government } \\
\text { and National Health Department. }\end{array}$ & Hierarch. & ION \\
\hline S4 & $\begin{array}{l}\text { Strategic Health Authority } \\
\text { (SHA) Region } 1\end{array}$ & $\begin{array}{l}\text { Pursues political goals and regional interests in health } \\
\text { area (Region 1). }\end{array}$ & Hierarch. & ION \\
\hline S5 & $\begin{array}{l}\text { Specialist in Process } \\
\text { Redesign }\end{array}$ & $\begin{array}{l}\text { To defend strategic issues for the performance } \\
\text { improvement of the processes implemented with the IOS. }\end{array}$ & Knowl./Abil. & External \\
\hline \multirow{2}{*}{ S6 } & \multirow{2}{*}{$\begin{array}{l}\text { In charge of Systems } \\
\text { Compatibility Organization } \\
\text { Y, Branch } 1\end{array}$} & \multirow{2}{*}{$\begin{array}{l}\text { Specify interaction requirements among information } \\
\text { systems already existing in Branch } 1 \text { of organization } Y \\
\text { and the IOS to be implemented. }\end{array}$} & Knowl./Abil. & \multirow{2}{*}{$\begin{array}{l}\text { Organiz. } \\
\text { (Pharmacy Y) }\end{array}$} \\
\hline & & & & \\
\hline
\end{tabular}

Table 10. Stakeholders Types-Roles Relationship for ICRS.

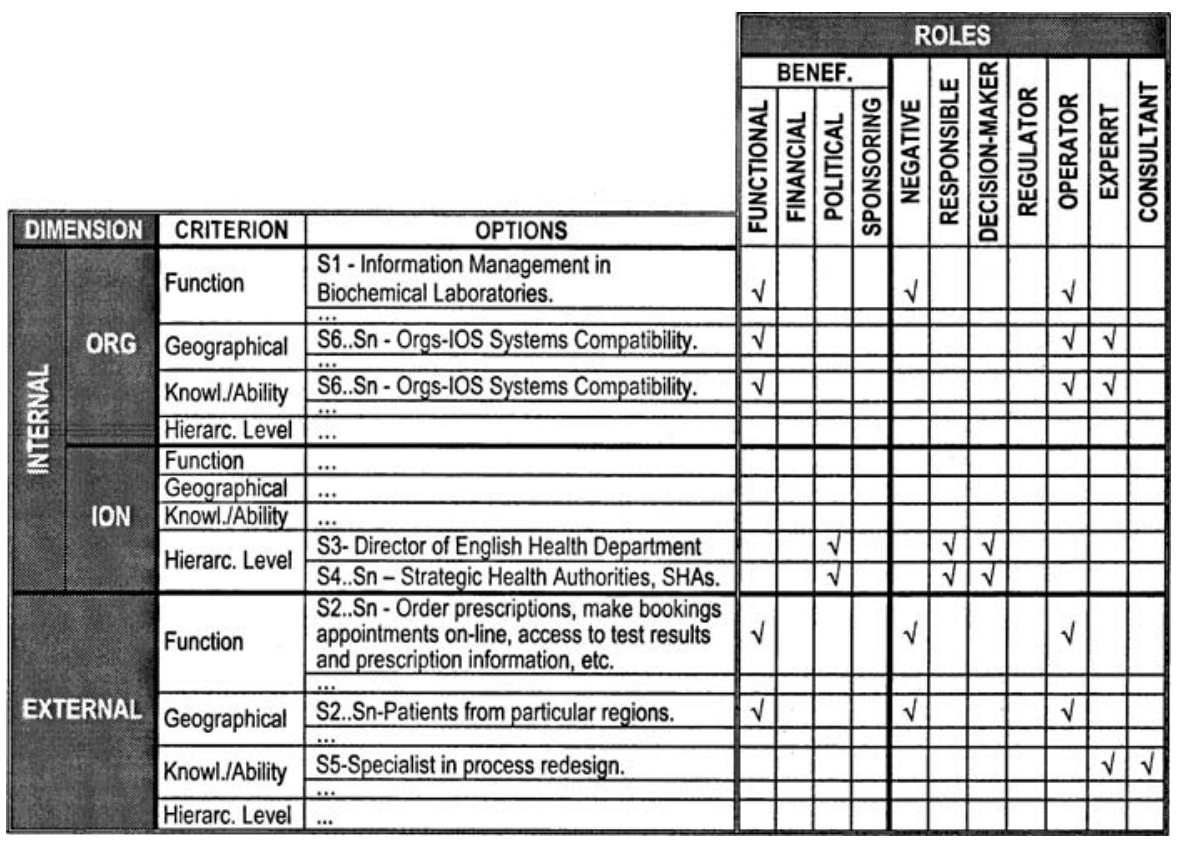

Table 11. Stakeholder Roles for ICRS.

\begin{tabular}{|l|l|l|}
\hline ID & \multicolumn{1}{|c|}{ STAKEHOLDER } & \multicolumn{1}{c|}{ ROLES } \\
\hline S1 & Biochemists Group Organization X & Functional Beneficiaries, Operators \\
\hline S2 & Patient A & Functional Beneficiaries \\
\hline S3 & Director English Department of Health & Political Beneficiary, Decision-Maker \\
\hline S4 & Strategic Health Authority Region 1 & Responsible, Decision-Maker \\
\hline S5 & Specialist in Process Redesign & Expert \\
\hline S6 & Responsible for Systems Compatibility Organization Y, Branch 1 & Expert \\
\cline { 1 - 2 }
\end{tabular}


Table 12. Stakeholders Interest and Influence for ICRS (Left).

Table 13. Stakeholders Matrix for ICRS (Right).

\begin{tabular}{|l|l|c|c|}
\hline ID & \multicolumn{1}{|c|}{ STAKEHOLDER } & TW. I IMP. & INFLUENCE \\
\hline S1 & Biochemists group Organization X & LOW & HIGH \\
\hline S2 & Patient A & HIGH & LOW \\
\hline S3 & Director English Department of Health & HIGH & HIGH \\
\hline S4 & Strategic Health Authority Region 1 & HIGH & HIGH \\
\hline S5 & Specialist in Process Redesign & HIGH & LOW \\
\hline S6 & $\begin{array}{l}\text { In charge of Systems Compatibility } \\
\text { Organization Y, Branch 1 }\end{array}$ & HIGH & LOW \\
\hline S7 & $\ldots$ & $\ldots$ & $\ldots$ \\
\hline
\end{tabular}

\begin{tabular}{|c|c|c|c|}
\hline & \multicolumn{2}{|c|}{ INFLUENCE } \\
\hline & & $\mathrm{HIGH}$ & LOW \\
\hline $5 \stackrel{u}{9}$ & 좀 & $\begin{array}{l}\text { S3 } \\
\text { S4 }\end{array}$ & $\begin{array}{l}\text { S2 } \\
\text { S5 } \\
\text { S6 }\end{array}$ \\
\hline 플응 & 오 & $\cdots$ & $\begin{array}{l}\text { S1 } \\
\ldots\end{array}$ \\
\hline
\end{tabular}

S2, S5 and S6 have high importance and low influence. Even though their viewpoint is essential, they have no control on the possibility of making crucial decisions for the project.

Regarding S3 and S4, their location in the quadrant denoting high importance and influence is due to the fact that they have power for decision making and influence on the project. In the NHS structure, they constitute different hierarchical levels. Politicians are the most interested parties and promoters of the project.

S1 was associated to high influence and low importance. According to the project manager's decision, requirements of this group do not constitute the main to be elicitated, and they have no influence on the decisions to be made in the project.

\section{Conclusions}

Stakeholders identification is a critical matter in software projects in general. IO environments introduce not only a new analysis dimension but also different interests and interactions that must be analyzed. This constitutes a challenge for the decisions that must be taken during the project at different levels. The existing related literature, however, does not provide practical guides to be systematically applied for selection in these environments. To overcome this, this work proposes a concrete methodology composed of steps for carrying out stakeholders' identification for interorganizational projects.

This proposal improves the already existing ones because is systematic, since it provides concrete tools to be applied considering all dimensions involved in these environments. It is also flexible, since new criteria for selection can be added to the methodology enhance the information and knowledge about the involved contexts. It is a concrete methodology that, in spite of being developed for contexts formed by multiple organizations, it may be also applied to traditional organizational contexts, avoiding the analysis of the proposed interorganizational dimension.

Acknowledgments: The authors want to thank the financial support from CONICET (Consejo Nacional de Investigaciones Científicas y Técnicas), Agencia Nacional de Promoción Científica y Tecnológica and UTN (Universidad Tecnológica Nacional) from Argentina.

\section{References}

1. K. Bittner, I. Spence, Establishing the Vision for Use Case Modeling, Use Case Modeling, Addison Wesley Professional, 2003.

2. A. Pouloudi, R. Gandecha, A. Papazafeiropoulou, C. Atkinson, How Stakeholder Analysis can Assist Actor-Network Theory to Understand Actors. A Case Study of the Integrated Care 
Record Service (ICRS) in the UK National Health Service, Eltrun Working Paper Series, WP 2004-002, 2004.

3. J. Giesen, A. Völker, Requirements Interdependencies and Stakeholders Preferences, IEEE Joint International Conference on Requirements Engineering (RE'02), 2002.

4. B. Nuseibeh, S. Easterbrook, Requirements Engineering: A Roadmap, ICSE, Conference on The Future of Software Engineering, 2000, pp. 35-46.

5. G.S.C. Pan, Information Systems Project Abandonment: A Stakeholder Analysis, International Journal of Information Management, 25(2), 2005, pp. 173-184.

6. A. Papazafeiropoulou, A. Pouloudi, A. Poulymenakou, Electronic Commerce Competitiveness in the Public Sector: The Importance of Stakeholder Involvement, Int. J. of Services Technology and Management, 3(1), 2002, pp. 82-95.

7. A. Pouloudi, Aspects of the Stakeholder Concept and their Implications for Information Systems Development, 32 Annual Hawaii International Conference on System Sciences. 1999. 8. H. Sharp, A. Finkelstein, G. Galal, Stakeholder Identification in the Requirements Engineering Process, DEXA Workshop 1999, pp. 387-391.

9. G. Kotonya, I. Sommerville, Requirements Engineering: Processes and Techniques, J. Wiley \& Sons Eds. 2003.

10. D. Chatterjee, T. Ravichandran, Inter-organizational Information Systems Research: A Critical Review and an Integrative Framework, 37th Hawaii International Conference on System Sciences, 2004.

11. A. Pouloudi, E.A Whitley, Stakeholder Identification in Inter-Organizational Systems: Gaining Insights for Drug Use Management Systems, European Journal of Information Systems, 6, 1997, pp. 1-14.

12. J. Coughlan, R.D. Macredie, Effective Communication in Requirements Elicitation: A Comparison of Methodologies, Requirements Engineering Journal, 7, 2002, pp. 47-60.

13. J. Jonker, D. Foster, Stakeholder Excellence? Framing the Evolution and Complexity of a Stakeholder Perspective of the Firm, Corporate Social Responsibility and Environmental Management, 9, 2002, pp. 187-195.

14. G. Khalifa, Z. Irani, L.P Baldwin, S. Jones, Evaluating Information Technology With You in Mind, Electronic Journal of Information Systems Evaluation, 4(1), 2001.

15. P. Gruenbacher, Integrating Groupware and CASE Capabilities for Improving Stakeholder Involvement in Requirements Engineering, Euromicro Workshop on Software Process and Product Improvement at 26th Euromicro Conference, 2000, pp. 2232-2239.

16. I.F. Alexander, A Better Fit - Characterising the Stakeholders, Requirements Engineering for Business Process Support (REBPS) 2004 Workshop, CAISE'04, 2004.

17. A. Kelvin, How stakeholders with various preferences converge on acceptable investment programs, Journal of Evaluation and Program Planning, 23, 2000, pp. 105-113.

18. J. Ropponen, K. Lyytinen, Components of Software Development Risk: How to Address Them? A project Manager Survey, IEEE Transactions on Software Engineering, 26(2), 2000.

19. V. Shankar, G.L. Urban, F. Sultan, Online trust: a stakeholder perspective, concepts, implications and future directions, J. of Strategic Information Systems, 11, 2002, pp. 325-344.

20. L. M. Applegate, Stakeholder Analysis Tool, Harvard Business Review, April, 2003.

21. J. Boutelle, Understanding Organizational Stakeholders for Design Success, Boxes and Arrows, May 2004. Available at: http://www.boxesandarrows.com/view/understanding_organi zational stakeholders for design success

22. A. Qualman, A Note on Stakeholder Analysis, Guidance Note on How to Do Stakeholder Analysis of Aid Projects and Programmes. Document prepared by the British Overseas Development Administration (ODA), Social Development Department. July 1995.

23. L.W. Smith, Project Clarity Through Stakeholder Analysis, CrossTalk, The Journal of Defense Software Engineering. December, 2000.

24. National Health Service, in: http://www.connectingforhealth.nhs.uk.

25. The Go Between Information for Information Users, 54, October, 2003. In: http://www. assist.org.uk/Branches/London/the go between/Go-Between\%20-\%20ISSUE54.pdf 